\title{
CROSS-CULTURAL COMMUNICATION AND COLLABORATION: CASE OF AN INTERNATIONAL E-LEARNING PROJECT
}

\author{
ElifToprak[etoprak1@anadolu.edu.tr],EvrimGenc-Kumtepe[egkumtepe@anadolu.edu.tr], \\ Anadolu University, Yunus Emre Campus Open Education Faculty Room No:607 26470 Eskisebir Turkey \\ [www.anadolu.edu.tr]
}

\begin{abstract}
Communication is an indispensable part of international cooperation and it requires managing different cultures. Being prepared to see and understand different values, trying to understand contrasting views in a consortium, can decrease the potential of misperception which otherwise may act as a real barrier to cooperation. This is why international cooperation necessitates negotiation across cultures. In the case of collaboration, parties come together for a joint work which itself may create common values/understanding, besides the set goals. This is because collaboration requires strong we-feeling and commitment. The purpose of this paper is to focus on cross-cultural communication and collaboration in the area of Open and Distance Learning (ODL), concentrating on the communication processes in project management. Cross-cultural studies point to different communicative behaviours of individuals in multinational work environments e.g. the cultural characteristics affect the preferences towards the use of the media. For the purposes of this paper, the authors make a phenomenological-oriented case study of project management based on interviews with partners of a multilateral Grundtvig (adult learning) project, affiliated with distance education institutions in eight different countries. The authors test their assumptions for constructive and cooperative communication in e-Learning projects; delineating the effects of different cultures as regards the expectations from (1) international projects and (2) communication media.
\end{abstract}

Keywords: Culture, communication, ODL, e-Learning, cross-cultural communication, project management.

\section{Introduction}

Owing to the new communication technologies, distance education has become borderless and specifically e-Learning is an area highly convenient for international cooperation. Due to its relevance with the use of technology and the luxury to reach large audiences, it is preferred by many institutions. Besides the pedagogical issues, the communication pillar for cooperation in this area is critical as well and necessitates great care for different socio-cultural contexts, values and expectations (Gunawardena \& LaPointe, 2008, p51). The previous experiences, patterns and communication protocols developed and used by different scholars in the field may help practitioners on their way.

Communication is an indispensable part of international cooperation and is the art of managing different mindsets since the parties in the communication process can perceive the same subject in different ways. People that work internationally and cross-culturally realize that their partners 
may reach very different conclusions from the same evidences (Fisher, 1997). Since the volume of international affairs and businesses increase every day and globalization multiplies this interdependence, it has become more important to use the mindset factor, which Fisher defines as the "differing patterns of perceiving and reasoning". A very important determinant of this mindset is culture.

International practitioners do not generally pay enough attention to the cultural and psychological dimensions of communication. In order to get over the barriers in international relations in a specific collaborative area, the practitioner needs to see the iceberg hidden from view and this requires more than knowledge of theoretical background on the issue. The starting point is a mindset open to tolerating different perceptions and being able to think in a multidisciplinary manner. This means that the practitioners cannot enjoy the luxury of concentrate on only one area, on the contrary they have to consider political, economic, social, psychological, technical and cross-cultural issues at the same time (Fisher, 1997). Thus an interdisciplinary methodology is pivotal in order to integrate the diverse information related with different areas and coming from different sources.

Gunawardena and LaPoint are among scholars that highlight the socio-cultural context for international distance education and they discuss the related dimensions. Among them, social presence, perception of time, differences in communication styles, ways of conflict resolution, language issues related to second-language speakers are especially noteworthy for the purposes of this paper questioning the cross-cultural communication processes and the use of media for cooperation in e-Learning projects (51). Globalization is generally blamed to hegemonize certain modes of conduct so that the Western ways of studying/working prevail over the local preferences. One of the frequently asked questions in the field is whether it is ethical to ignore the cultural differences for the sake of acting in similar ways or not. Collaboration needs certain common understanding and codes for parties to get on well with each other and act together. However completely neglecting the cultural differences might cause communicational problems and prevent joint action for common goals around a project.

\section{Cross-cultural Communication}

Since culture is related with values, ideas, beliefs communicated from one generation to another, it is an issue open to be perceived in different ways. Culture is an individual, psychological and social construct (Gunawardena \& LaPointe, 2008, pp53-4). Thus when studying the role of culture in communication, basic concepts need to be clarified and operationally defined. Barnett and Lee classify intercultural, international and cross-cultural communication. Intercultural communication is the exchange of cultural information between groups of people with different cultures. International communication is the exchange of messages between nation states, organizations. International (comparative) communication studies are concerned with mass media, comparing national media infrastructures and policies. Cross-cultural communication research on the other hand compares the cultural groups and studies the implications of the differences for the processes of communication.

Communication takes place as the information is exchanged among two or more social systems for a certain purpose. The general aim is to reduce the uncertainty and create an understanding between interactants (Gudykunst, 2003). Culture is composed of values, beliefs, customs and thought patterning which are models for perceiving and interpreting the messages. In Geert Hofstede's words: "Culture is more often a source of conflict than of synergy. Cultural differences are a nuisance at best and often a disaster." Especially if the objective is international cooperation, these differences cannot be underestimated. Hofstede's theoretical framework consists of certain dimensions of 
cultural variability based on; individualism-collectivism, power-distance, uncertainty avoidance, masculinityfemininity (Hofstede, 1986, p301). These dimensions point out the importance of the socio-cultural context of the relations and the effects of values and experiences of the parties in the communication processes. Among these dimensions; individualism stands for the situation whereby any person that primarily looks after his/her own interests and those of immediate family. On the other hand, collectivism means a permanent loyalty to a certain group, causing the individual to give priority to the closely integrated group s/he belongs to. Secondly, power distance denotes the degree to which less powerful members of a society take inequality for granted. Hofstede explains that though inequality exists in all societies, the level of tolerance to it, changes from one to culture to another. Thirdly, uncertainty avoidance reflects the extent of tolerance which members of a society show, in the face of unstructured, unclear circumstances, so this is reflected by whether they seek strict codes of behavior or not. The last dimension is based on masculinity versus femininity, which is related with the social roles recognized in a society for men and women. Basically speaking, masculine societies motivate men to be ambitious and competitive for material success and women to be supportive for the non-material quality of life where interpersonal relations and concern for the weak matter most (1986, pp307-8). Thus masculine societies maximize the social sex role division whereas in feminine societies, sex roles have smaller part in determining the social roles (Hofstede, 1983, p45). Hofstede classified over 50 countries according to these dimensions and compared their interactions in teaching/learning environments, project management and work places. The results of his analyses also shed light on the discussion made for the purposes of this study and efforts to understand different contexts for collaboration and partnership. A fifth dimension was added later on, following a study conducted by Chinese scholars based on the choice of focus for showing effort, whether the motivation for joint work is short or long term oriented (Wang \& Reeves, 2007, p5).

Culture is socially shared and learned; just as is international collaboration. Culture for a certain task also develops for international collaboration for certain period of time, in a certain field for specific common goals and interests. This is what project management is about. These common values and we-feeling are again generated via established norms, values and principles by a certain group of people. This common understanding also determines the way the group members communicate with each other. Generally speaking, the regulation of international relations in a certain issue area is named as a "regime" that is composed of common rules and norms. However there are more than norms in a regime to consider if functional or dysfunctional cooperation patterns exist. In this connection, common values, cultural backgrounds and experiences of the participants affect the way they act and what they expect from their interaction with their partners. As the social constructivist theory of international relations argues, cooperation is a sociological concept that is based on learning common values (Toprak, 2006). The sense of community is created in an environment with diversity of values and perspectives that intermingle creating a new pattern and way for collaboration of the group.

Another factor in building cooperation is the media used. A famous quotation from Marshall McLuhan "the medium is the message" underlines that medium determines the scale and form of human action. Most of the time it is not the content but the medium itself that shapes the behaviours (McLuhan, 1964, pp7-9). One of the basic assertions in McLuhan's work is that in all electric media the user must learn to be involved in communication process in order to become co-producer (McLuhan \& Zingrone, 1995, p5) and affect the content and following processes. "The new electronic interdependence recreates the world in the image of a global village..." (1995, p127). In this connection, the use of new communication technologies in project management has its own peculiarities to be considered. The internet and online communication environments provide stimuli for joint action. As Bates puts forth, if learning to work collaboratively online is an important skill for the $21^{\text {st }}$ century, then this skill itself must be a goal to be achieved in online learning and working environments (Bates, 2001, p132).

European Journal of Open, Distance and e-Learning - Vol. 17 / No. 1 
In the case of project management, cultural differences need to be categorized so that comprehension barriers do not lead to conflicts in the project consortium. Basic categories of cultural dimensions are life rhythms, time consciousness, time divisions and information density. Generally speaking the coordinator may either choose a dominating central culture and/or totally neglect the cultural differences. However, better knowing and getting used to these differences increases the success of the team, especially in case the strengths of different cultures are used for creating synergy. There are certain issues important for managing the cultural differences; these are (1) position of the project for the coordinator and the partner organizations (2) standardization of the rules and procedures (3) adaptation of instruments of project management according to the rising needs (Schneider, 1995, p249). In the case of EU (European Union) financed projects, the procedures and instruments are given through the EU Commission and these create an environment conducive for cooperation.

Jarvenpaa and Leidner (1998) drive our attention to characteristics of global virtual teams and the problems they face in asynchronous and synchronous computer-mediated communication. The cases they report on, suggest that these teams experience a "swift" trust which is very fragile and temporal. This is why they debate on how to facilitate trust in cross-cultural virtual teams that heavily rely on virtual interaction only. Face-to-face interaction is generally considered irreplaceable for building trust, project teams that meet face-to-face are a step forward in this sense as they have opportunity for social relationship building. Other factors that may lead to building trust and/or repair shattered trust are shared social norms, experiences and repeated interactions. Team members from individualistic cultures are suggested to be more open to trusting others in computer-mediated communication environments when compared with individuals from collectivist societies. Jarvenpaa and Leidner also indicate that global virtual teams do not build trust, they import it from other settings they are familiar with. Temporary work teams with diverse skills, very limited history of working together are in a tendency to link trust with their joint/common action. Timely response in communication is another important factor in facilitating this cooperation. It is argued that electronic media may even hinder cultural/linguistic differences in cases where the team members never meet face-to-face but communicate via emails and web chats.

There are also authors who criticize the constructed national identities and languages, indicating that all EU sponsored ODL (Open and Distance Learning) projects are the result of transnational cooperation and thus may contradict with the ethno linguistic democracy model of the EU. This is because projects may run on "lingua franca" determined according to the consensus of business people and citizens taking part in projects. The working principles of the multicultural ODL environments and projects take the heterogeneity of cultures as a fact and manage linguistic issues according to mutual agreements among parties (Van den Branden \& Lambert, 1999, p256).

Another term developed by management scholars is cross-cultural competence in international business. This is an individualistic approach that stresses some attributes of project managers such as certain attitudes, skills and knowledge for leadership. Referencing Hofstede, scholars emphasize that cross-cultural competence can be taught to managers, however personal traits are effective in acquiring them as well. Showing sensitivity to cultural differences, being able to maintain social relations with the given cultural group(s), speaking their language(s) and knowing the institutional structures in other culture(s) are among the points underlined in the general definition of this competence (Johnson et al., 2006, p529). These are issues that need to be considered in the case of project management since it is mostly up to the coordinator to avoid cultural misunderstandings and motivate the team towards the project goals (Anbari et al., 2004, $\mathrm{p} 267)$. It is important to recognize, respect, and reconcile the cultural differences (p272). 


\section{Research Method}

The research design for this study was structured to employ a phenomenological-oriented case study to investigate the reactions and perceptions of those involved in the phenomenon (project management) by interviewing participants (project team members). "Phenomenology aims at gaining deeper understanding of the nature or meaning of our everyday experiences" (van Manen, 1990). The underlying phenomenon, herein, was communication experiences of partners in the project management processes of a cross-cultural project. In particular, it was intended to better understand the essence of the cross-cultural communication process as perceived by each project partner. It was anticipated that working in a multicultural group could yield different lived experience and relationships. The literature on cross-cultural project management emphasizes the need to consider the cultural differences seriously and manage them to the advantage of the common objectives.

The phenomenon of intercultural discussion has been seen to be an anthropological issue (Müller-Palzer, 2011). In the past years, research efforts have tried to answer "what it means if two people from a different culture are interacting and try to communicate successfully or experience conflicts and misunderstanding". When studying culture and communication in a specific context, social, cultural, contextual and historical dynamics could explain the potential differences in human acts, relationship and also how they perceive such communication in certain places. Lindqvist (2012) implies that a perception can never be exactly same for two people due to different former experiences, angle of perception, mental orientation, cultural backgrounds etc. Indeed, this enables the particular experience of the phenomenon to be individual. In other words, the constitution process of meaning one attributes to intercultural communication is partly unique to this individual (p22). Therefore, the current attempt was to describe what it means for a person to communicate with another person from a different culture. More specifically, we need to understand better this phenomenon where people (project team members) perceived crosscultural communication and how they make sense of the interaction in the case of an international project environment. It is with this understanding that phenomenology was chosen as the practice of inquiry.

\section{Case Study: Project ELBEP (Eliminating Language Barriers in European Prisons through Open and Distance Education Technology)}

Project ELBEP was a multilateral cooperation project under the Grundtvig Programme1. The consortium established for the objectives of the project consisted of partners from eight different countries: Turkey, Netherlands, Poland, Belgium, Germany, UK, Greece, and Russia. Two of the partners from the Netherlands and the UK (with office in Hungary) were international NGOs (EADTU and EDEN) in ODL field that already have the notion and culture for cooperation and networking. The coordinating partner was Anadolu University from Turkey and the project duration was two years (2007-2009). The project aimed to promote cross-cultural dialogue and meet the communication needs of prison staff members in the EU countries, regarding the foreign prisoners they encountered in their work environment. The project was designed to meet the criteria for the Association of Language Testers in Europe (ALTE) A1 level in order to develop products that could later on be certified and accredited in European countries. ELBEP focused on Russian, Polish, Spanish, Greek and Turkish language needs of the EU prison staffs, since foreign prisoners speaking these native languages compose important percentages in European prisons. The expected impact of teaching beginner's level second languages to European prison staff, via flexible ODL media, was seen as an alternative to solve the communication problems. In this connection, ELBEP would promote intercultural 
understanding, tolerance for diversity and lead to a suitable environment where rehabilitation and adult education of prisoners could be more achievable.

The eight project partners of ELBEP held a number of face-to-face project meetings in different locations throughout the two year life span of the project. The partners also had regular online meetings. Every week, team member conference was organized online via the project portal. In addition to the face-to-face meetings and online chat sessions, the members in the teams utilized e-mail and phone calls for communication. The electronic communication media were utilized predominantly for project management purposes.

\section{Data Collection and Analysis}

Observation during the web meetings and face-to-face project meetings (in Eskisehir, Hagen, Antwerp, Athens, Izmir) and interviews conducted during the last meeting with the partners were the mainstay of data collection for the overall study. Since the respondents had already been involved in many distance education projects, they might be evaluated to be biased towards international cooperation in this field. However the research question revolved around "how they perceived the effect of culture on the consortium and its communication processes". Basically stated, the key parameter was the level of understanding each other in a cross-cultural network for the purposes of project management.

Partners (project teams from eight countries) were asked to share their ideas on the advantages of European consortiums and their perception about the effects of cultural traits on preferences for communication tools and negotiation styles. Specifically, the questions were what the partners learned from working in a multicultural group and what they felt was important in working with a culturally diverse group, how they perceived and handled conflicts or problems if they encountered any, and which tools they used most frequently to communicate and access information during the project. The participants of the last project meeting in İmir were interviewed and those who did not attend were sent interview questions via email and asked to give feedback. The preset themes based on theoretical background of Hofstede's dimensions and Gunawardena's conceptual framework were guided to the data analysis and presenting findings. Firstly, the field notes and the statements of interviews were read for overall understanding and every expression relevant to experience was listed. Then the significant statements of project members were interpreted according to preset themes. However, there were a number of emergent themes as well, which were individual and institutional cultural differences among team members, rather than national differences.

\section{Findings and Discussion}

As part of the query, partners have indicated e-mailing as a more convenient and the most frequently used tool for communication. They generally believed that the project portal has been applicable when an in-depth analysis or discussion by the partners was deemed necessary at the pre-determined chat sessions. Using e-mails instead of telephone calls, msn chats and Skype services seemed to be a way of avoiding uncertainty for all the partners. The practicality of saving the messages also supported the mentality behind this preference for e-mailing. Still some partners emphasized the difficulty of reaching consensus on the schedule of the chat sessions though the medium was considered as a good opportunity for the discussions related with research problems. At this point, the time difference and the different daily routine responsibilities of the partners played pivotal role. A partner has driven attention to technical problems and stated that: 


\begin{abstract}
Chat rooms are not available from our university because of some blocking technologies used by the Internet provider. I could participate in chat sessions from my apartment only and it was not convenient as I was not able to change places rather quickly.
\end{abstract}

The same respondent has commented that:

\title{
Chat sessions during summer were extremely useful. If only technical problems had not prevented me from taking part in them.
}

The social presence required for effective communication and learning in online environments is important also for establishing a sense of community for collaborative work. The three dimensions of social presence; social context, online communication and interactivity have been at work (Gunawardena \& LaPointe, 2008, p58). Despite different cultural perceptions and lifestyles of the partners, promptness in answering each other's emails and attendance to regular chat sessions were important to complement the face-to-face project meetings. The coordinator played an important role for facilitating the chats and building trust among partners. There was consensus among partners on the importance of punctuality and timely reactions to raised issues. Though when looked through Hofstede's lenses, half of the partners were from societies with high individuality index (Germany, Netherlands, Great Britain and Belgium) collectivist approaches were applied more. At this point the cultural traits of the coordinator (from Turkish culture) defined as collectivist, large power distance, strong uncertainty avoidance and feminine perspective could have overwhelmed the others' trends (Hofstede, 1986, pp309-310).

As regards the ideas on the advantages of European consortiums in general and the effects of culture on cooperation; the majority of the respondents believed that the cultural differences did not cause barriers to communication or cooperation. One respondent replied:

\section{...the advantages lay more in the differences in professional expertise than national/ cultural.}

Another respondent has ironically emphasized the European consortiums as a mean of eliminating cultural barriers and acquiring knowledge and experience of international cooperation itself. However, cooperation in e-Learning field also denotes sharing expertise in learning technologies; seeing different pedagogical approaches and methodologies and better understanding of one's own place in the European community. Besides the requirements for computer-mediated communication, ODL projects necessitate other skills as well, this is why technical skills come prior to other factors specified by Gunawardena such as language, power distance, gender differences, collectivist versus individualist tendencies, conflict management, social presence and time frame in this case-study (2008, p62).

During some chat meetings, the discussions proved to be difficult and they had to be managed by the moderator (from the coordinating organization) via using high-context communication, providing the backgrounds of the issues, prior negotiations about the topics in order to prevent misunderstandings. Some partners referenced this environment to different cultural identities of the partners. On the other hand some team members that were more accustomed to international collaboration believed that this situation emanated from the lack of collaborative work/project culture. The latter group emphasized the importance of project leadership to overcome the negotiation problems and believed that partners less experienced in the subject social learning process for joint work needed more facilitation.

For international projects, legal frameworks and specific bureaucracies are not the only norms partners learn, but the processes for negotiation and communication are also socially experienced and learned. Partners became more familiar with which administrative and communicative tools to use as they gained more experience during the project. The coordinator was asked to take the European Journal of Open, Distance and e-Learning - Vol. 17 / No. 1 
initiative and decide for all parties, when it was hard to reach consensus. The project consultant who was an ODL expert with German nationality advised the coordinator many times to act decisively. This could be due to the characteristics Hofstede stresses for the German culture; strong uncertainty avoidance and masculinity (being self-assertive) (see Figure 1). However, these tendencies may also be related with the personal traits of the individuals. On the other hand, none of the project partners raised the language factor as a barrier, though there was no native English speaker in the project and all communication was in English. As stated by the team members, during both chat meetings and the face-to-face meetings, language did not pose any serious communication problem.

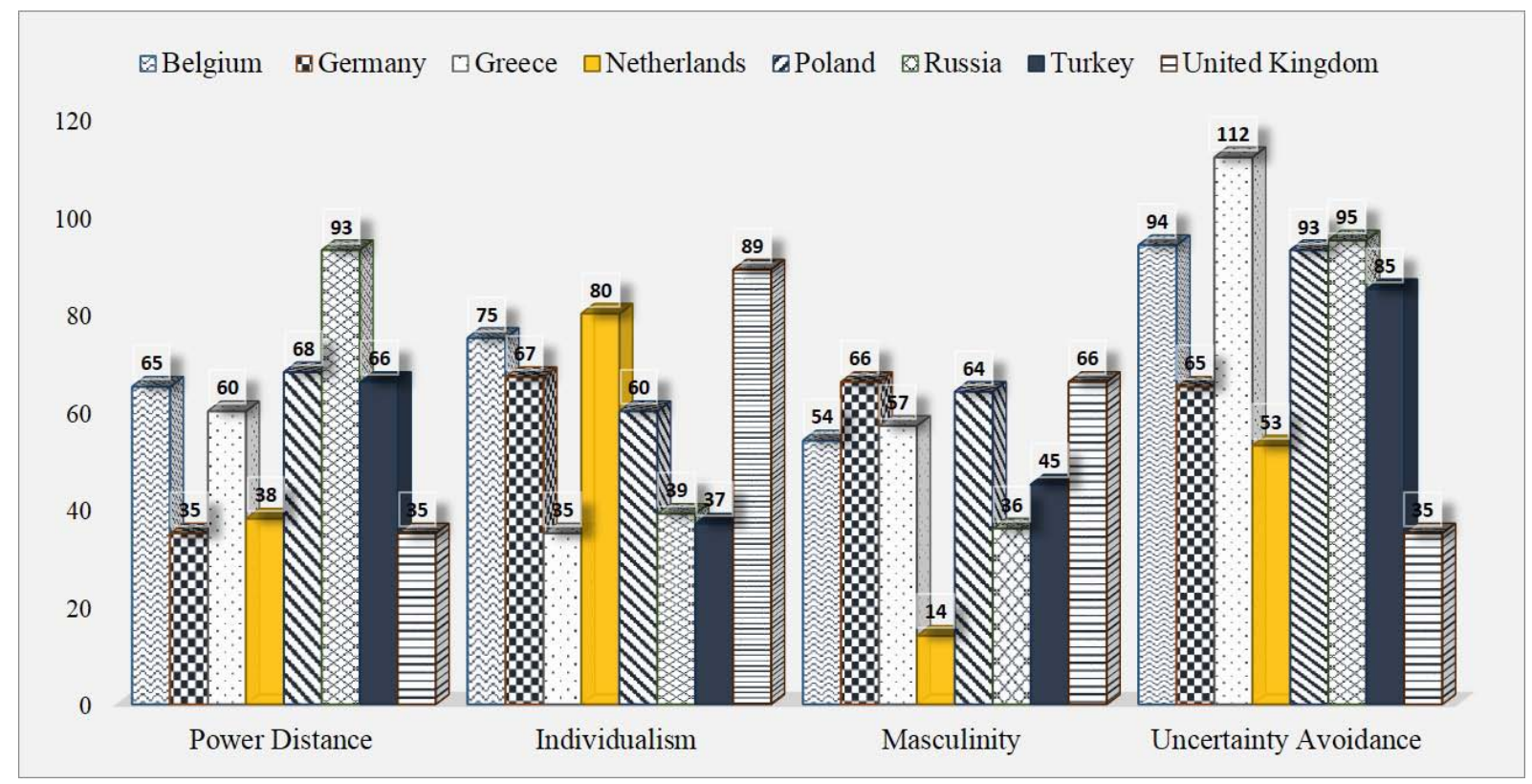

Figure 1. Comparing project partners' national cultural dimensions along with Hofstede's model

A respondent has explained her ideas in the following words:

\section{...I think the way we communicate in an international consortium in general and in the ELBEP group in particular is based on our personality and personal experience rather than our general cultural background.}

The reason for the emphasis on the professional background of the partners and the international project experience is also because the partners were expected to communicate with a certain jargon of ODL and manner for the civility of the interaction. Though there was no written code for communication, the partners were careful and sensitive about their correspondence. One of the respondents was however rather hesitant about the effect of cultural differences and replied:

I think for our project, differences should not matter but maybe I am mistaken.

Another comment was:

... of course cultural traits affect the way we communicate. It is easy to communicate with the persons from our own culture, because we use the same code...but cooperation opens new worlds for us and broadens the mind.

No matter which level and source of cultural differences the partners experienced and drove attention; they did not ignore them at all. However, they did not always see sociocultural characteristics as the main factors but personal traits and experiences as the main reason of the 
differences in expectations, preferences and evaluations during the communication processes which were really the backbone of the project management task. This tendency to emphasize the personal traits reflects an individualistic approach in seeking cultural interaction. The systemic approach and caution about the deadlines and the tasks specified in the work packages stem from the uncertainty avoidance dimension of Hofstede's cultural model. Still though, the classification according to the cultural dimensions should be carefully discussed without exaggerating their effects and showing care to unique circumstances of each collaboration and cross-cultural study. Individuals can lead to exceptional differences in communication and project management processes and this must not be underestimated. In general project members did not see national cultural differences as causing problems, they associated the problems with changing levels of experience in ODL projects and cross-cultural studies. The mentoring role of the two partners EDEN and EADTU in project management also strengthens this assertion, since their expertise in networking and familiarity with multicultural working environments served as models and eased administrative processes.

When it comes to comparative analysis, it is interesting that partners from Poland, Russia and Turkey emphasized the effects of cultural diversity more than others, as a reason for communicational problems. This tendency may have emanated from their positions vis-à-vis the EU. Poland is member, but Turkey and Russia are not member states of the Union. Turkey is in negotiation with the Commission and is in the stage of learning and applying the acquits. For international cooperation and business in general, the case of European projects have an advantage since they have their own format and jargon that bring the different bureaucracies of the partner institutions together. A strong project leadership can overcome the communication barriers with expertise. This becomes more manageable with the EU projects in the form of a learning process since the framework and road maps are supported with the Community documents. However, for the EU member countries the process of cooperation itself is something they are more familiar with in their daily lives; they have integrated most of their procedures and regulations. Besides this idea of integrity with the European way of doing things, the tendency to look through the lens of cultural differences may be related with where the societies stand in Hofstede's classification.

In terms of power distance, Turkey, Russia and Poland are all hierarchical societies, especially Russia is among the most hierarchical ones given the very clear-cut tasks in the society. As regards individualism vs. collectivism, while Polish culture is more individualistic, Russian and Turkish societies are collectivist with strong family ties. Thirdly, about masculinity and femininity; Russia is clearly feminine which means that there is more emphasis on the quality of living and social life is not success driven. In this regard, Turkey is in the middle of the scale however closer to the feminine side where there is care for the weak. In practice, sexes are very effective on the choice of social roles, more than Hofstede's work statistically shows (see Figure 1). Contrarily, Poland is a more masculine society which is driven by competition. Some tensions during the project management and communication processes seem to have arisen because of these different perspectives to life. All three societies have high preference for avoiding uncertainty which means that they feel threatened by ambiguities. The anxieties about the project procedures and continuous need for information updates by the coordinator may be explained on the bases of these factors.

The cultural biases in project management may be overcome by equal treatment of all partners and getting to know each other first by reading about the cultural characteristics of different societies. Still, individual perceptions as emphasized in research findings, must be taken into consideration and generalizations must be refrained from when evaluating the online communication processes. The usability of the media, context, technology, language are factors that have to be cross-checked. In the literature, two important critiques about Hofstede's studies 
are (1) his emphasis on nations as the units for studying culture and (2) that the answers of his respondents cannot be generalized to represent entire national cultures. Hofstede has answered such criticisms stressing that comparison through nations is better than nothing (Wang \& Reeves, 2007, pp5-6), though generalization is dangerous and sub-national cultures, individualistic differences affect the communicative and collaborative skills of individuals and teams.

\section{Conclusion and Suggestions}

Cross-cultural studies and international projects provide environments where communication processes are pivotal in the direction of the collaboration in hand. As the field of co-work gets closer and opens to the ICT applications, it gets even more complex and deserves more attention to the use of media and management of communication processes. The technology both empowers the individuals in interaction but may create room for alienation due to cultural differences. The cultural differences may not come from national roots only but from individual and institutional characteristics as well. In the subject case-study, the common expertise of the partners in ODL field, have led team members to speak the same terminology and the general sensitivity of the project to cultural and linguistic diversity in Europe has made partners more careful about communicative processes. The project dwelled on teaching foreign languages online and the project management and communication processes did not suffer from cultural and linguistic problems most probably because of the attention given to understanding each other and solving problems timely as soon as they occurred. The pre-planned face-to-face meetings eased the socialization process and the creation of we-feeling. As ODL experts, all team members were used to electronic media for communication. The research findings indicate that it has been the general perception of the partners that the national cultural differences have not been barriers for project management. However the hesitation on this assertion by Turkish, Russian and Polish partners support Hofstede's classification of western and eastern cultures; subject partners belonging to the latter one. Still this hesitation may also be read according to the proximity to the European culture for joint work.

In ELBEP, small communication problems did not discourage the partners, many of them even did not associate the problems with socio-cultural differences but underlined the importance of different institutional cultures and individual experiences for coping with problems. Some controversies arose but were managed through strong leadership of the coordinator which the partners themselves approved to be applied. As regards collaborative online environments, cooperation in distance education is no exception. Particularly for the management of international projects, seeing the consortiums as multinational workplaces is a must. The overall recommendations of the authors of this study, derived from literature on cross-cultural project management and their own project experience in ELBEP as team members can be summarized as follows:

- Interoperability: The parties must propose cooperation to the institutions they believe that they can work with;

Choosing a partner not well known institutionally and has not been cooperated with before may generate a risk. This is an issue, parties need to evaluate when making their intentions clear.

- Operating guidelines: Project management guideline of the organization financing the joint study/work must be utilized;

The guideline establishes a common ground (norms, values, beliefs) and increases the predictability of the collaborative process.

- Key stakeholders: International governmental and non-governmental organizations (NGOs) are preferred partners due to their networks and environments conducive to international studies; 
These organizations and their representatives are already open-minded for different perceptions and bureaucracies for working together. They are also good at networking and match-making to bring potential partners together. Their reference for the member institutions also increases the credibility of the consortiums established.

- ICT inclusion: The global culture of the information society and the use of ICT motivate and ease communication for cooperation;

Despite the different cultural characteristics of the partners and more specifically different organizational cultures and procedures that affect the concert of the consortiums, the institutions in the same field and at the same technology level use similar media for communication. The common denominator is especially the Internet which is utilized for effective communication and web based learning environments.

- Social Learning Experience: International cooperation is a social learning process; The parties must be well aware that the joint working environments themselves are learning processes where partners form unique groups and get to know each other and their previous experiences. Each project is a different case due to the parties involved and/or the issue co-studied. It is difficult to make generalizations according to this assumption, but the experiences and literature lead practitioners to check their own lists via benchmarking.

- Cultural effects at macro and micro levels: The culture so the value orientations of the nations and institutions are effective on individual perceptions of practitioners, especially the decision-makers;

The group dynamics and decision-making processes are affected by the values inherited and learned socially however project partners are not always government officials/bureaucrats. It may be difficult for them to adapt to different legal procedures. Their advantage is that they can be more flexible in their attitudes and receptive when compared with the diplomatic envoy e.g. sometimes it may be more difficult to understand the idea behind a procedure rather than the procedure itself.

- Perceptions: Each partnership is unique, due to the nature of the joint task and the composition of the consortium;

At this point, culture and perception enter our scene playing their leading roles. Their effects can be analyzed at two levels, national and/or institutional. At least trying to understand the changing reactions and contrasting views may decrease the potential for misperception so that it does not act as a barrier to cooperation. Institutions operate according to their own domestic and organizational culture and this explains why international cooperation means negotiation across cultures, especially when it is time for decision-making in terms of problem-solving.

As regards the case of cooperation for e-Learning, the factors influencing the relations get little more complicated due to the technical issues. Though the use of the ICTs and new web based learning environments bring a common terminology and technology to build cooperation on, cultural differences and preferences at different levels (social, organizational even individual) may lead to difficulties. The changing priorities and needs of the institutions may divert the common interests. It is mainly the organizational frameworks, networks and projects funded by institutions like the European Commission, just as in the subject case that may bring a cooperative framework and generate a cooperation culture common to all partners.

The authors, with this study have questioned their assumptions about cross-cultural collaboration in ODL field, based on a phenomenological-oriented case study. The two main outcomes are (1) the pivotal role of the technical issues related with the choice of media, and (2) the changing perceptions about cultural diversity, arising from individual and organizational differences rather than from nationalities. Coming to European projects, it can be argued that they pose less communication problems among partners due to their clearly defined goals and guidance by the Commission. Though European projects seem to support the convergency hypothesis (Hofstede, European Journal of Open, Distance and e-Learning - Vol. 17 / No. 1 
1983, p41) of 1970s about convergence of liberal management styles, unity in diversity is the motto of the EU and the effects of cultural diversity have been long recognized. The subject of this study does not reflect significant national cultural differences in communication and problem-solving styles however, other project stories may teach completely different lessons.

\section{References}

1. Anbari F.T.; Khilkhanova, E.V.; Romanova, M.V. and Umpleby, S.A. (2004). Managing cultural differences in international projects. In Journal of International Business and Economics, 2(1), (pp. 267-74).

2. Barnett, G.A. and Lee, M. (2003). Issues in intercultural communication research. In W. B. Gudykunst (ed.), Cross-cultural and intercultural communication, (pp. 259-273). USA: Sage Publications.

3. Bates, T. (2001). International distance education: Cultural and ethical issues. In Distance Education, 22(1), (pp. 122-36).

4. Fisher, G. (1997). Mindsets: The role of culture and perception in international relations. Yarmouth, USA: Intercultural Press Incorporated.

5. Gunawardena, C.N. and Lapointe, D. (2008). Social and cultural diversity in distance education. In T. Evans, M. Haughey, D. Murphy (eds.), International Handbook of Distance Education, (pp. 51-70). UK: Emerald Publishing.

6. Gudykunst, W.B. (2003). Issues in cross-cultural communication research. In W. B. Gudykunst (ed.), Cross-cultural and intercultural communication, (pp. 149-161). USA: Sage Publications.

7. Jarvenpaa, S.L. and Leidner, D.E. (1998). Communication and trust in global virtual teams. In Journal of Computer-Mediated Communication, 3(4), doi: 10.1111/j.1083-6101.1998.tb00080.x

8. Johnson, J.P.; Lenartowicz, T. and Apud, S. (2006). Cross-cultural competence in international business: toward a definition and a model. In Journal of International Business Studies, 37, (pp. 525-43).

9. Hofstede, G. (1983). Cultural dimensions for project management. In Project Management, 1(1), (pp. 41-48).

10. Hofstede, G. (1986). Cultural differences in teaching and learning. In International Journal of Intercultural Relations, 10, (pp. 301-320).

11. Hofstede G.'s website pages on cultural dimensions: http://www.geert-hofstede.com, http://geert-hofstede.com/russia.html, http://geert-hofstede.com/turkey.html, http://geerthofstede.com/poland.html

12. Koehn, P.H. and Rosenau, J.N. (2002). Transnational competence in an emergent epoch. In International Studies Perspectives, 3, (pp. 105-127).

13. Lindqvist, M. (2012). Intercultural communication at the work place: An explorative study using a phenomenological approach. Unpublished thesis. Lunds University.

14. McLuhan, M. (1964). Understanding Media: The Extensions of Man. UK: Routledge.

15. McLuhan, E. \& Zingrone, F. (1995). Essential McLuhan. UK: Routledge.

16. Müller-Pelzer, W. (2011). Intercultural competence: A phenomenological approach. In A. Witte \& T. Harden (eds.), Intercultural Competence: Concepts, Challenges, Evaluations. Intercultural Studies and Foreign Language Learning. Vol. 10. 
17. Schneider, A. (1995). Project management in international teams: instruments for improving cooperation. In International Journal of Project Management, 13(4), (pp. 247-51).

18. Toprak, E. (2006). Social constructivism and international cooperation in distance education. In TOJDE, 7(3), (pp. 174-183). http://tojde.anadolu.edu.tr/tojde23/index.htm

19. Van den Branden, J. and Lambert, J. (1999). Cultural issues related to transnational open and distance learning in universities: A European problem? In British Journal of Educational Technology, 30(3), (pp. 251-60).

20. Van Manen, M. (1990). Researching lived experience: Human science for an action sensitive pedagogy. The University of Western Ontario: Althouse Press.

21. Wang C.M. and Reeves, T.C. (2007). The meaning of culture in online education: Implications for teaching, learning and design. In A. Edmundson (ed.), Globalized e-Learning cultural challenges, (pp. 1-17). USA: Information Science Publishing.

22. Ziguras, C. (2008). Cultural and contextual issues in the evaluation of transnational distance education. In T. Evans, M. Haughey, D. Murphy (eds.), International Handbook of Distance Education, (pp. 639-651). UK: Emerald Publishing.

\footnotetext{
${ }^{1}$ For the final report of the project; http://elbep.anadolu.edu.tr/ElbepFinalReportPublic.pdf; for project website; http://elbep.anadolu.edu.tr
} 